\title{
The kinematics Analysis of Running on Multi- Inclination (comparative study)
}

\section{*Dr /Hani Abdol Aziz Saleh}

\section{Research Problem:}

Refers to Gary Kamen, Dr. Gordon J Robertson \& Graham J Caldwell, \& Joseph Hamill, Saunders N, Whittlesey (2004), the importance of the mechanical analysis is to reach a correct movement details and identify reasons excellence or failure. (13: 146)

And the running is the most important abilities and skills essential for many sports activities as it represents the preliminary stage for many of competitions in sports, such as jumping competitions, and floor movements, space in gymnastics is an important and a major part in the acquisition of the appropriate amount Movement to accomplish duty motor skill.

Through theoretical studies from that seen by the researcher, which touched on the study of running using a multi-inclination, researcher has observed that it was determined the physiological effect of Running, also found equations determine the physiological effort reality as a result of running through equations endorsed by the American College of Sports Medicine. (16) (Annex 1).

Were extracted table shows the relationship between the running time and running inclination angle and rate of calorie burning in the body (annex 2).

While the researchers did not address to the knowledge of to the analysis biokinematics to run on a multiinclination, Therefore, the researcher studied biokinematics analysis to run on multi-inclination, which is the indicator of the presence of Kinetics changes between the three methods of running under study, and then directing those bio-kinematics parameters to take advantage including

" Lecturer in Sport Training and Movement Science Department, Faculty of Physical Education for (Men- Girls) in Port-Said, Port-Said University, A.R.E Associate professor at Faculty of education - Physical Education \& Movement Science Department, Al Qassem University, K.S.A 
training in operations, as it seeks to research and identify the best way to run the appropriate goal of running a multi-inclination.

\section{Research Aims:}

The research aims to Kinematics analysis to run on a multi- inclination, in order to determine the Kinematics characteristics of the body during running and comparing them and reach a pregnancy, mechanical reality on the athlete's body, in order to recruit and adapt these parameters learned to take advantage of them, through the identification of:

- Kinematical characteristics of Running on zero Angle.

\section{Research Symbols:}

measurement Symbol

$\mathrm{Sec} \quad \mathrm{T}$ Time

Cm Dx Horizontal displacement Component

$\mathrm{Cm} \quad$ Dy Vertical displacement Component

$\mathrm{Cm} / \mathrm{sec} \quad \mathrm{Vx} \quad$ Horizontal Velocity

$\mathrm{Cm} / \mathrm{sec} \quad \mathrm{Vy} \quad$ Vertical Velocity

$\mathrm{Cm} / \mathrm{sec}^{2} \quad \mathrm{Ax} \quad$ Horizontal Acceleration

$\mathrm{Cm} / \mathrm{sec}^{2} \quad$ Ay $\quad$ Vertical Acceleration

Research Methodology:

The researcher used the descriptive method by using Kinematical analysis, as this is more suitable for the nature of the research

\section{Research Simple:}

- Kinematical characteristics of

- Kinematical characteristics of Running on negative Angle.

- Kinematics differences between the three methods to running on a multi-inclination.

\section{Research Questions:}

- what are the Kinematical characteristics of Running on zero Angle?

- what are the Kinematical characteristics of Running on positive Angle?

- what are the Kinematical characteristics of Running on negative Angle?

- what are the Kinematics differences between the three methods for running on a multi-inclination?

Term Running on positive Angle. 
- running on positive Angle $\left(+15^{\circ}\right)$

- running on negative Angle ($15^{\circ}$ )

Anthropometric collection tools
Biomechanics Data collection tools

Capture, 2D Video:

By Gopro hero4 black Camera (240fbs)

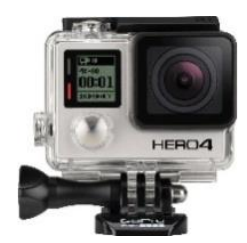

Figure (1) Gopro hero4 black Camera

Biomechanics analysis by "Kinonea" software:

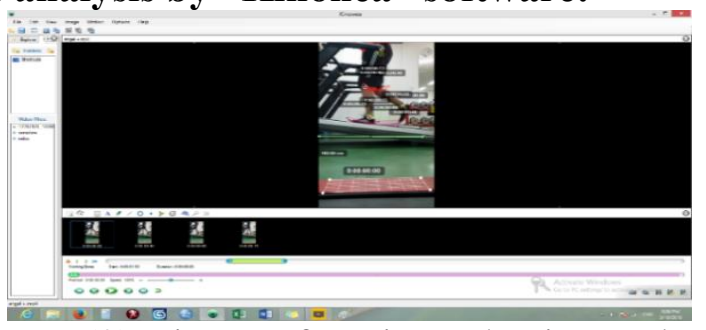

Figure (2) Kinonea for Biomechanics analysis

The researcher used (thigh - leg - foot) in two axes "Kinonea" for kinematics analysis of running to four points represent three segments

(horizontal $\mathrm{x}$, vertical $\mathrm{y}$ ) to get Kinematical variables in three phases as the following:

\begin{tabular}{|c|c|c|c|c|c|c|c|c|}
\hline \multicolumn{9}{|c|}{ Kinematics analysis model to run a multi-mile left to the man } \\
\hline \multicolumn{9}{|c|}{ (thigh - leg - foot) } \\
\hline \multicolumn{3}{|c|}{ running } & \multicolumn{3}{|c|}{ runnii $\quad f$ Angle } & \multicolumn{2}{|c|}{ running } & \\
\hline $1^{\text {nd }}$ Early & $2^{\text {ed }}$ Mid & $3^{\text {th }}$ Late & $1^{\text {nd }}$ Early & $2^{\text {ed }}$ Mid & $3^{\text {th }}$ Late & $1^{\text {nd }}$ Early & $2^{\text {ed }}$ Mid & $3^{\text {th }}$ Late \\
\hline Float & Pivot & Float & Float & Pivot & Float & Float & Pivot & Float \\
\hline
\end{tabular}

\begin{tabular}{|c|c|c|c|c|c|c|c|}
\hline \multicolumn{7}{|c|}{ Kinematics analysis model to run a multi-mile left to the man } \\
\hline \hline & & \\
\hline
\end{tabular}

Assiut Journal For Sport Science Arts 


\begin{tabular}{|c|c|c|c|c|c|c|c|c|}
\hline $\mathrm{t}$ & $\mathrm{t}$ & $\mathrm{t}$ & $\mathrm{t}$ & $\mathrm{t}$ & $\mathrm{t}$ & $\mathrm{t}$ & $\mathrm{t}$ & $\mathrm{t}$ \\
\hline disablement & disablement & disablement & disablement & disablement & disablement & disablement & disablement & disablement \\
\hline $\mathrm{xy}$ & $\mathrm{xy}$ & $\mathrm{xy}$ & $\mathrm{xy}$ & $\mathrm{x} \mathrm{y}$ & $\mathrm{x} \mathrm{y}$ & $\mathrm{x} \mathrm{y}$ & $\mathrm{xy}$ & $\mathrm{x} \mathrm{y}$ \\
\hline velocity & velocity & velocity & velocity & velocity & velocity & velocity & velocity & velocity \\
\hline $\mathrm{x} \mathrm{y}$ & $\mathrm{x} \mathrm{y}$ & $\mathrm{xy}$ & $\mathrm{xy}$ & $\mathrm{x} \mathrm{y}$ & $\mathrm{x} \mathrm{y}$ & $\mathrm{x} \mathrm{y}$ & $\mathrm{x} \mathrm{y}$ & $\mathrm{x} \mathrm{y}$ \\
\hline Acceleration & Acceleration & Acceleration & Acceleration & Acceleration & Acceleration & Acceleration & Acceleration & Acceleration \\
\hline $\mathrm{x} \mathrm{y}$ & $\mathrm{xy}$ & $\mathrm{x} \mathrm{y}$ & $\mathrm{xy}$ & $\mathrm{xy}$ & $\mathrm{xy}$ & $\mathbf{x y}$ & $\mathrm{x} \mathrm{y}$ & $\mathrm{xy}$ \\
\hline \multicolumn{9}{|c|}{ (Knee - ankle) } \\
\hline Time & Time & Time & Time & Time & Time & Time & Time & Time \\
\hline $\mathrm{t}$ & $\mathrm{t}$ & $\mathrm{t}$ & $\mathrm{t}$ & $\mathrm{t}$ & $\mathrm{t}$ & $\mathbf{t}$ & $\mathrm{t}$ & $\mathrm{t}$ \\
\hline Angular & Angular & Angular & Angular & Angular & Angular & Angular & Angular & Angular \\
\hline disablement & disablement & disablement & disablement & disablement & disablement & disablement & disablement & disablement \\
\hline $\mathrm{Da}$ & $\mathrm{Da}$ & $\mathrm{Da}$ & $\mathrm{Da}$ & $\mathrm{Da}$ & Da & Da & Da & Da \\
\hline Angular & Angular & Angular & Angular & Angular & Angular & Angular & Angular & Angular \\
\hline velocity & velocity & velocity & velocity & velocity & velocity & velocity & velocity & velocity \\
\hline $\mathrm{Va}$ & $\mathrm{Va}$ & $\mathrm{Va}$ & $\mathrm{Va}$ & $\mathrm{Va}$ & $\mathrm{Va}$ & Va & $\mathrm{Va}$ & $\mathrm{Va}$ \\
\hline Angular & Angular & Angular & Angular & Angular & Angular & Angular & Angular & Angular \\
\hline acceleration & acceleration & acceleration & acceleration & acceleration & acceleration & acceleration & acceleration & acceleration \\
\hline $\mathrm{Aa}$ & $\mathrm{Aa}$ & $\mathrm{Aa}$ & $\mathrm{Aa}$ & $\mathrm{Aa}$ & $\mathrm{Aa}$ & Aa & $\mathrm{Aa}$ & $\mathrm{Aa}$ \\
\hline Angle ${ }^{\circ}$ & Angle ${ }^{\circ}$ & Angle ${ }^{\circ}$ & Angle ${ }^{\circ}$ & Angle ${ }^{\circ}$ & Angle ${ }^{\circ}$ & Angle ${ }^{\circ}$ & Angle ${ }^{\circ}$ & Angle ${ }^{\circ}$ \\
\hline
\end{tabular}

Figure (3) Kinematics analysis model to run a multi-mile left to the man

Results:

Present the results of the Time analysis:

Table (1)

The Averages of kinematics analysis of the Time analysis

\begin{tabular}{l|c|c|c|c|c|c|c}
\hline \hline & \multicolumn{2}{|c|}{$\mathbf{1}^{\text {st }}$ phase } & \multicolumn{2}{|c|}{$\mathbf{2}^{\text {nd }}$ phase } & \multicolumn{2}{|c|}{$\mathbf{3}^{\text {rd }}$ phase } & \multirow{2}{*}{ Sum } \\
\cline { 2 - 7 } & Sec & $\%$ & Sec & $\%$ & Sec & $\%$ & \% \\
\hline $\begin{array}{l}\text { running on zero } \\
\text { Angle }\end{array}$ & 0.30 & $40 \%$ & 0.20 & $26 \%$ & 0.26 & $34 \%$ & 0.76 \\
\hline $\begin{array}{l}\text { running on } \\
\text { positive Angle }\end{array}$ & 0.40 & $50 \%$ & 0.23 & $29 \%$ & 0.17 & $21 \%$ & 0.80 \\
\hline $\begin{array}{l}\text { running on } \\
\text { negative Angle }\end{array}$ & 0.36 & $42 \%$ & 0.24 & $28 \%$ & 0.26 & $30 \%$ & 0.86 \\
\hline \hline
\end{tabular}

Present the results of the running on zero Angle analysis:

Table (2)

The Averages of kinematics analysis to running on zero Angle for segments

\begin{tabular}{l|l|l|l|l|l|l|l|c}
\hline \hline serial & segment & phases & $\mathrm{dx}$ & $\mathrm{dy}$ & $\mathrm{vx}$ & $\mathrm{vy}$ & $\mathrm{ax}$ & $\mathrm{ay}$ \\
\hline \hline
\end{tabular}

Assiut Journal For Sport Science Arts 


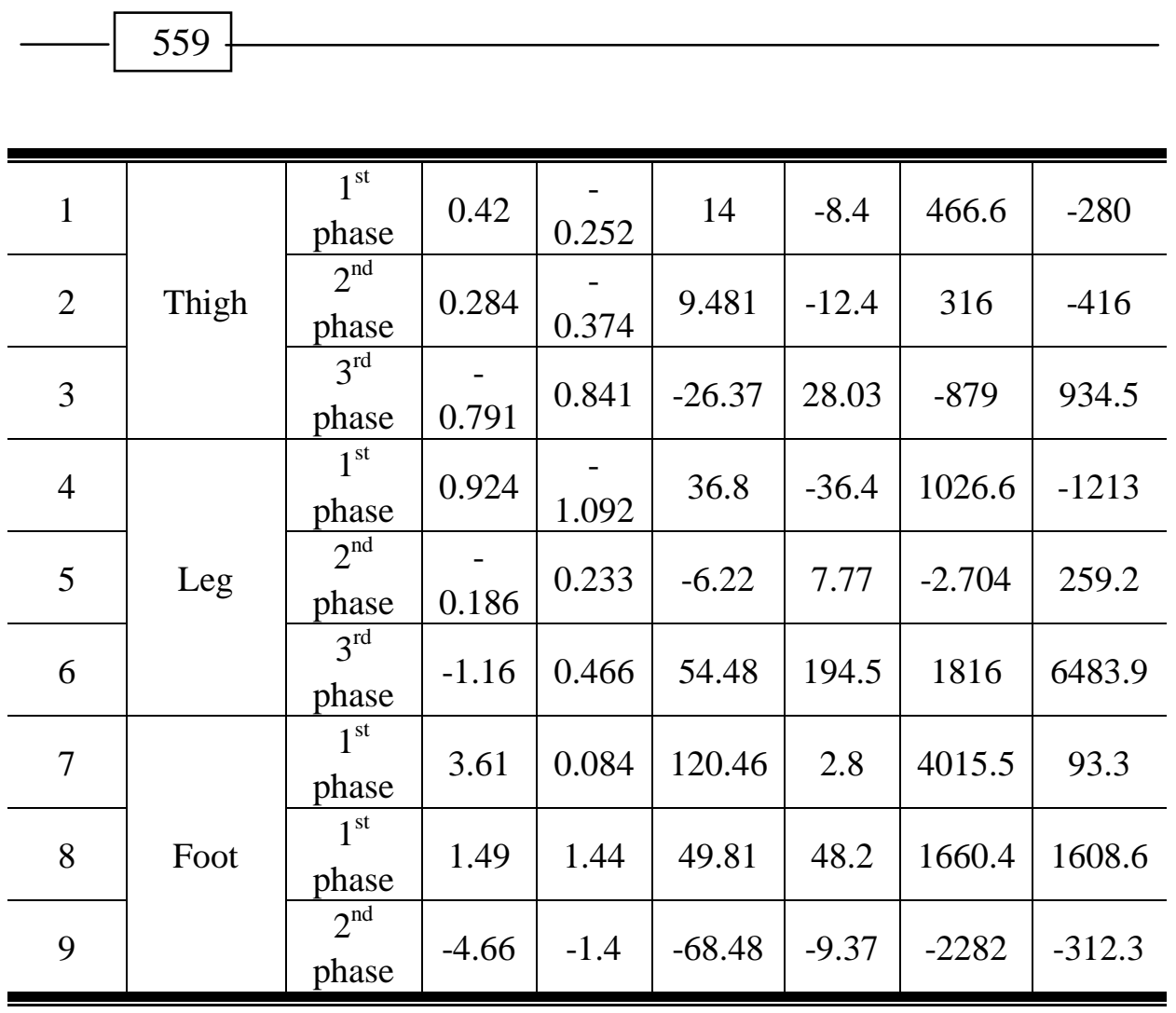

Table (3)

The Averages of kinematics analysis to running on zero Angle for body Angles

\begin{tabular}{|c|c|c|c|c|c|}
\hline serial & segment & phases & $\bar{d}$ & $\overline{\mathbf{v}}$ & $\overline{\mathbf{a}}$ \\
\hline 1 & \multirow{3}{*}{ knee } & $1^{\text {st }}$ phase & -19 & -95 & -475 \\
\hline 2 & & $2^{\text {nd }}$ phase & 23 & 76.6 & 255.5 \\
\hline 3 & & $3^{\text {rd }}$ phase & 28 & 107.6 & 414.2 \\
\hline 4 & \multirow{3}{*}{ ankle } & $1^{\mathrm{st}}$ phase & 36 & 180 & 900 \\
\hline 5 & & $1^{\mathrm{st}}$ phase & -44 & -146.6 & -488.8 \\
\hline 6 & & $2^{\text {nd }}$ phase & -1 & -308 & -14.7 \\
\hline
\end{tabular}

Present the results of the running on positive Angle analysis: 
Table (4)

The Averages of kinematics analysis to running on positive Angle for segments

\begin{tabular}{|c|c|c|c|c|c|c|c|c|}
\hline serial & segment & phases & $d x$ & dy & $\mathbf{v x}$ & $\mathbf{v y}$ & $\mathbf{a x}$ & ay \\
\hline 1 & \multirow{3}{*}{ Thigh } & $\begin{array}{c}1^{\text {st }} \\
\text { phase }\end{array}$ & -0.11 & -0.41 & -3.72 & $\begin{array}{c}- \\
13.72\end{array}$ & -124.2 & -457.5 \\
\hline 2 & & $\begin{array}{c}2^{\text {nd }} \\
\text { phase }\end{array}$ & 0.058 & $\begin{array}{c}- \\
0.234\end{array}$ & 1.95 & -7.80 & 65.07 & -260.3 \\
\hline 3 & & $\begin{array}{c}3^{\text {rd }} \\
\text { phase }\end{array}$ & 0.13 & 0.823 & 4.55 & 27.44 & 151.8 & 914.81 \\
\hline 4 & \multirow{3}{*}{ Leg } & $\begin{array}{c}1^{\text {st }} \\
\text { phase }\end{array}$ & 1.87 & 0.042 & 62.36 & 1.24 & 2078.7 & 41.41 \\
\hline 5 & & $\begin{array}{l}2^{\text {nd }} \\
\text { phase }\end{array}$ & -2.83 & -1.00 & -94.33 & -33.3 & -3144 & -1112 \\
\hline 6 & & $\begin{array}{c}3^{\text {rd }} \\
\text { phase }\end{array}$ & -0.19 & 1.37 & -6.55 & 45.83 & -218.5 & 1527.7 \\
\hline 7 & \multirow{3}{*}{ Foot } & $\begin{array}{c}1^{\text {st }} \\
\text { phase }\end{array}$ & 2.95 & 0.523 & 98.515 & 17.45 & 3283.8 & 581.8 \\
\hline 8 & & $\begin{array}{c}1^{\text {st }} \\
\text { phase }\end{array}$ & -1.82 & 0.647 & -60.76 & 21.57 & -2025 & 719 \\
\hline 9 & & $\begin{array}{l}2^{\text {nd }} \\
\text { phase }\end{array}$ & $\begin{array}{c}- \\
3.291\end{array}$ & -1.57 & -109.7 & $\begin{array}{c}- \\
52.61\end{array}$ & -3257 & -1753 \\
\hline
\end{tabular}

Table (5)

The Averages of kinematics analysis to running on positive Angle for body Angles

\begin{tabular}{c|c|c|c|c|c}
\hline \hline serial & segment & phases & $\mathbf{d}$ & $\mathbf{v}$ & $\mathbf{a}$ \\
\hline \hline 1 & \multirow{3}{*}{$k n e e$} & $1^{\text {st }}$ phase & -6 & -15 & -37.5 \\
\cline { 4 - 6 } & $2^{\text {nd }}$ phase & -27 & -117.3 & -510.3 \\
\cline { 4 - 6 } & $3^{\text {rd }}$ phase & 31 & 182.3 & 1072.6 \\
\hline 3 & \multirow{3}{*}{ ankle } & $1^{\text {st }}$ phase & 26 & 65 & 162.5 \\
\cline { 4 - 6 } & $1^{\text {st }}$ phase & -22 & -95.6 & -415.8 \\
\cline { 4 - 6 } & $2^{\text {nd }}$ phase & -2 & -11.7 & -69.2 \\
\hline \multirow{2nnnyyy}{*}{6} & &
\end{tabular}

Present the results of the running on negative Angle analysis: 
Table (6)

The Averages of kinematics analysis to running on negative Angle for segments

\begin{tabular}{|c|c|c|c|c|c|c|c|c|}
\hline serial & segment & phases & $\mathbf{d x}$ & dy & $\mathbf{v x}$ & vy & $\begin{array}{l}\mathbf{a x} \\
\end{array}$ & ay \\
\hline 1 & \multirow{3}{*}{ Thigh } & $\begin{array}{c}1^{\mathrm{st}} \\
\text { phase }\end{array}$ & 1.08 & -0.65 & 34.93 & $\begin{array}{c}- \\
21.83 \\
\end{array}$ & 1164 & -727.7 \\
\hline 2 & & $\begin{array}{c}2^{\text {nd }} \\
\text { phase }\end{array}$ & $\begin{array}{c}- \\
0.435\end{array}$ & 0.25 & $\begin{array}{c}- \\
14.52\end{array}$ & 8.33 & -484.1 & 277.7 \\
\hline 3 & & $\begin{array}{c}3^{\text {rd }} \\
\text { phase }\end{array}$ & 0.29 & 0.24 & 9.70 & 8.07 & 323.45 & 269.12 \\
\hline 4 & \multirow{3}{*}{ Leg } & $\begin{array}{c}1^{\mathrm{st}} \\
\text { phase }\end{array}$ & 2.44 & -0.26 & 81.5 & $\begin{array}{c}- \\
8.733 \\
\end{array}$ & 2716.6 & -291.1 \\
\hline 5 & & $\begin{array}{c}2^{\text {nd }} \\
\text { phase }\end{array}$ & -1.99 & $\begin{array}{c}- \\
0.061\end{array}$ & 66.52 & -2.04 & -2217 & -68.25 \\
\hline 6 & & $\begin{array}{c}3^{\text {rd }} \\
\text { phase }\end{array}$ & $\begin{array}{c}- \\
0.291\end{array}$ & 0.14 & -9.70 & 4.85 & -323.8 & 161.72 \\
\hline 7 & \multirow{3}{*}{ Foot } & $\begin{array}{c}1^{\text {st }} \\
\text { phase }\end{array}$ & 3.93 & 0.305 & 131 & 1.16 & 4366.6 & 338.8 \\
\hline 8 & & $\begin{array}{c}1^{\text {st }} \\
\text { phase }\end{array}$ & 0.151 & 1.56 & 5.04 & 52 & 168.2 & 1733.3 \\
\hline 9 & & $\begin{array}{c}2^{\text {nd }} \\
\text { phase }\end{array}$ & $\begin{array}{c}- \\
3.707\end{array}$ & -1.65 & $\begin{array}{c}- \\
123.5\end{array}$ & -55 & -4119 & -1833 \\
\hline
\end{tabular}

Table (7)

The Averages of kinematics analysis to running on negative Angle for body Angles

\begin{tabular}{c|c|c|c|c|c}
\hline \hline serial & segment & phases & $\mathbf{d}$ & $\mathbf{v}$ & $\mathbf{a}$ \\
\hline \hline 1 & \multirow{3}{*}{$k n e e$} & $1^{\text {st }}$ phase & -37 & -102.7 & -285.4 \\
\cline { 4 - 6 } & $2^{\text {nd }}$ phase & 13 & 54.1 & 225.6 \\
\cline { 4 - 6 } & $3^{\text {rd }}$ phase & 44 & 275 & 1718.75 \\
\hline 3 & \multirow{3}{*}{ ankle } & $1^{\text {st }}$ phase & 7 & 19.4 & 54.01 \\
\cline { 4 - 6 } & $1^{\text {st }}$ phase & -4 & -16.6 & -69.4 \\
\cline { 4 - 6 } & & $2^{\text {nd }}$ phase & -1 & -6.25 & -39.0 \\
\hline 4 & & &
\end{tabular}

Present the results of body Angles (under study) on Multi-Inclination running: 
Table (8)

The Averages of kinematics analysis to body Angles on MultiInclination running

\begin{tabular}{|c|c|c|c|c|c|}
\hline serial & segment & phases & $\begin{array}{c}\text { zero } \\
\text { Angle }\end{array}$ & $\begin{array}{c}\text { positive } \\
\text { Angle }\end{array}$ & $\begin{array}{c}\text { negative } \\
\text { Angle }\end{array}$ \\
\hline 1 & \multirow{3}{*}{ knee } & $1^{\text {st }}$ phase & $118^{\circ}$ & $146^{\circ}$ & $123^{\circ}$ \\
\hline 2 & & $2^{\text {nd }}$ phase & $141^{\circ}$ & $119^{\circ}$ & $136^{\circ}$ \\
\hline 3 & & $3^{\text {rd }}$ phase & $169^{\circ}$ & $150^{\circ}$ & $180^{\circ}$ \\
\hline 4 & \multirow{3}{*}{ ankle } & $1^{\text {st }}$ phase & $101^{\circ}$ & $123^{\circ}$ & $109^{\circ}$ \\
\hline 5 & & $1^{\text {st }}$ phase & $107^{\circ}$ & $101^{\circ}$ & $105^{\circ}$ \\
\hline 6 & & $2^{\text {nd }}$ phase & $106^{\circ}$ & $99^{\circ}$ & $104^{\circ}$ \\
\hline \multicolumn{3}{|c|}{$\begin{array}{l}\text { Discussion } \\
\text { - discusses the result of the } \\
\text { first question "what are the } \\
\text { Kinematical characteristics } \\
\text { of Running on zero Angle?" } \\
\text { As is evident from Table (1) } \\
\text { that the first phase is more } \\
\text { stages takes time, followed by } \\
\text { the third phase and then } \\
\text { followed by a second stage. } \\
\text { This is consistent with Laura } \\
\text { Hutchison, et al. (2014), } \\
\text { Tomas Haugen et al. (2015), } \\
\text { J.D. Willson et al. (2016) that } \\
\text { the first phase, which includes } \\
\text { touching foot to run and even } \\
\text { the background is the largest } \\
\text { weighted time-consuming } \\
\text { stages, and that this stage is the } \\
\text { most important in the running. } \\
\text { Also agree with Tomas Haugen } \\
\text { et al. (2015), Karsten } \\
\text { Hollanedr, et al. (2014), Laura } \\
\text { Hutchison, et al. (2014), in that } \\
\text { the running velocity it depends }\end{array}$} & $\begin{array}{l}\text { mainly } \\
\text { run, } \\
\text { basis } \\
\text { and d } \\
\text { step r } \\
\text { signifi } \\
\text { length } \\
\text { be m } \\
\text { during } \\
\text { to th } \\
\text { relativ } \\
\text { stage } \\
\text { freque } \\
\text { this sta } \\
\text { tables } \\
\text { charac } \\
\text { of ze } \\
\text { speed } \\
\text { focal } \\
\text { as the } \\
\text { horizo }\end{array}$ & $\begin{array}{l}\text { the first } \\
\mathrm{h} \text { is deterr } \\
\text { vhich the } \\
\text { rmine th } \\
\text { hing, also } \\
\text { tly to de } \\
\text { the step, } \\
\text { tained by } \\
\text { nning. } \\
\text { e research } \\
\text { fact that } \\
\text { mportance } \\
\text { determini } \\
\text { and inc } \\
\text { can be se } \\
\text { 2), (3) } \\
\text { istics to } r \\
\text { it was } \\
\text { the foot, } \\
\text { nt during } \\
\text { st segmer } \\
1 \text { distance. } \\
\text { is is con } \\
\text { T, et }\end{array}$ & $\begin{array}{l}\text { ase of the } \\
\text { ned on the } \\
\text { uscle tone } \\
\text { frequency } \\
\text { contribute } \\
\text { rmine the } \\
\text { which will } \\
\text { the body } \\
\text { attributes } \\
\text { the large } \\
\text { the first } \\
\text { the step } \\
\text { ased time } \\
\text { from the } \\
\text { inematical } \\
\text { an angle } \\
\text { he biggest } \\
\text { hich is the } \\
\text { he run, so } \\
\text { moving in } \\
\text { stent with } \\
\text { l. (2014) }\end{array}$ \\
\hline
\end{tabular}


Karzysztof Machala, et al. (2013) in the angular velocity of the articulated knee and ankle inversely proportional to the step frequency, this means that the wider the knee and ankle angle, the lower the frequency, so the foot is considered the most segment moving during the run.

The researcher attributes this to whenever the knee angle widened the greater stride length and therefore less frequency in the case of the body to maintain your running velocity.

As it can be seen that the largest acceleration was to leg in the third stage and attribute the researcher, however, that in the third phase of the player seeks to fling foot back at full velocity (Late-Float) so as to ensure the relay step and maintain the frequency and amplitude step.

Thus, the answer to the first question of the study achieved a "what are the Kinematical characteristics of Running on zero Angle?"

- discusses the result of The Second question "what are the Kinematical characteristics of Running on positive Angle?"
Is evident from Table (1) that the step in running a positive angle greater than it takes to run on zero angle, and the researcher is attributed to the rising of treadmill led to increased mechanical load on the muscles actually when running.

Since the law which states that: $\mathrm{F}=\mathrm{BM}+(\mathrm{BM} * \sin \theta)$

Means that the muscles involved in running actually working to push the mass of $(88.11 \mathrm{~kg})$. That means the muscles working pay approximately $(18.11 \mathrm{~kg})$ an average of approximately $(25.8 \%)$ plus the original body mass.

Hence unclear why increase the time period for the step due to the forces of gravity attract center of mass back and down.

And is evident from Table that the greatest velocity on the axis $\mathrm{x}$ was at the foot in the third phase as well as the velocity on the $y$ axis and the researcher attributes to that the third phase in the kind of run that includes raising the foot higher than the normal rate up as a result of surface run high an increase from the normal range with $\left(15^{(}\right)$, what agree 
with the results of table (8), in which it is clear that the knee angle was in the third stage $\left(150^{(}\right)$.

This is consistent with Darryl Cochrane, et al. (2013), the results of the training step run and modify the behavior of the muscle of the most important factors that contribute to the distribution of time on performance phases properly and typical.

As is consistent with Laura Hutchison, et al. (2014), Tomas Haugen et al. (2015) and J.D. Willson et al. (2016), that the third phase, which includes touching foot to running surface and even the late float are the most important in determining the beginning of the next step while running.

As it can be seen from the table (5) to the angular acceleration of the knee was $\left(1072.6 \mathrm{~m} / \mathrm{s}^{2}\right)$, the researcher attributes to that the player had in this type of run that tends his trunk forward with the aim of pushing the weight of the body center forward to overcome the weight of the back and the resulting level rise running from the front. By increasing the acceleration of the knee overcome the body's resistance to the decline of the body back. This is consistent with Deepak Kumar et al. (2015) while running the body is exposed to several mechanical factors affecting the shape of the body and therefore subject to change over Clenching the weight of the body.

Thus, the answer to the second question of the study achieved a "what are the Kinematical characteristics of Running on positive Angle?"

discusses the result of The Third question "what are the Kinematical characteristics of Running on negative Angle?"

Is evident from Table (1) that the total time to run at about $(0.86 \mathrm{~s})$ and it is the biggest time of the three species under study, although the tendency moving treadmill down helps to increase the velocity by pushing the weight of the body's center forward down, it helps to increase your running velocity.

The researcher attributes this to the part played into contact with the ground-heeled foot first so as to prevent increasing of the weight of the 
body out of the center of the vertical axis for him, which caused stopping the rush of the body in front of the (brake) through the feet.

This was clear from the results table (8), reaching the knee angle in the third phase $\left(180^{\circ}\right)$ means that the knee angle at this phase was on a straight line.

This is consistent with the results of Table (6) reaching horizontal velocity of the foot in the second phase of about $(5.04 \mathrm{~m} / \mathrm{s})$, while in the same period amounted to vertical velocity of about the same foot $(52 \mathrm{~m} / \mathrm{s})$.

This is consistent with the study of each of Deepak Kumar et al. (2015), J.D. Willson et al. (2016), which shows that the mechanical factors that effect in body while running affect in the shape of the body, which requires the player to change its center of gravity by tendency the body continues to overcome variable mechanical factors surrounding the change. Attribute the researcher to the player, while running at an angle is negative (down), it is redistributing the weight of the body center back and so awry trunk back and this in turn leads to minimize the length of the step and relying on running the individual knee fully and the descent of the heel first in a control action in the weight of the body center and prevent tilt forward.

Which is consistent with the results of a study Bradley S. Neal, et al. (2016), which shows that the Force Platform shows that changing the running surface level lead to a re-foot pressure distribution on the surface in proportion to the change in the weight of the body center.

Thus, the answer to the third question of the study achieved a "what are the Kinematical characteristics of Running on negative Angle?"

discusses the result of the fourth question "what is the Kinematics differences between the three methods to running on a multiinclination?"

\section{Differences in the time variable:}

Seen from the tables (1) differences between the performances of the forms of running under study, where the first phase took $26 \%, 50 \%$ and 
$42 \%$ of the total time to run on zero Angle and positive angle and a negative angle of inclination, respectively.

Attribute the researcher so that the law of motion on surface incline: $\mathrm{F}=\mathrm{B} \cdot \mathrm{M}+(\mathrm{B} \cdot \mathrm{M} *$ $\operatorname{sine} \theta$ ). (In case running on positive angle) $\mathrm{F}=\mathrm{B} . \mathrm{M}$ (B.M*sine $\theta)$.). (In case running on negative angle)

In the second form of running (running inclination angle is positive), the body mass increase about $17.5 \mathrm{~kg}$ of the original mass of the body $(70 \mathrm{~kg})$ so the muscles involved in running operates from (1) to pushing mass (87.5 $\mathrm{kg})$.

This is causing an increase of the first phase of the run, which will last points of touching the foot of the land to late float of the foot, which is the basic point that the body depends on it to push the body forward.

While the second phase takes about 40\%, 29\% and $28 \%$. This is consistent with the study of Bradley S. Neal, et al. (2016), Deepak Kumar et al. (2015), which showed the results of that phase starts from the end of the late float to convergence feet at one point that considered less stages exert force is the second stage in the order time-consuming, While seen from Table (1) and figure (5) that run at a negative angle took the second stage less than a third phase.

The researcher attributes this to the body is resisting descend down while running reverse muscle working thus slowing down the run in the third stage, which in turn leads to increased time for the third phase of the second stage.

Since the law which states that: $\mathrm{F}=\mathrm{B} \cdot \mathrm{M}$ - (B.M*sine $\theta)$. ). (In case running on negative angle)

Any muscles involved in running actually work to push the amount of mass $(52.5 \mathrm{~kg})$ mean that the muscles working with $(75 \%)$ of the original body mass.

\section{differences in the variables of linear velocity and acceleration:}

Seen from the tables (2), (4), (6) that there is a difference in the variable velocity during the running on zero angle incline, and running on positive angle and running negative angle, where it is clear that the horizontal velocity in the first stage was in the 
running-zero angle greater than all the rest of the methods of running under study.

The researcher attributes this to the running on negative angle was helping bode to gain velocity, although the small time, and it shows that while running on the negative angle of a tendency is the step length small, which increases legs velocity.

While the vertical velocity was in favor of running inclination angle zero. Researcher attributes this to the difference in the vertical displacement of anatomical points while running inclination angle zero bigger than in the running inclination angle positive up and running at right angles negative, causing an increase legs velocity.

Which is consistent with the study of Darryl Cochrane, et al. (2013), Laura Hutchison, et al. (2014), Tomas Haugen et al (2015).

As is clear from (2), (4), (6) that there are differences in the acceleration for the body segments under study, where the acceleration on the $\mathrm{x}$-axis largest at running to on negative angle, followed by running on angle of zero followed by running at angle positive.

The researcher attributes this to the fact that the negative incline gives the player a mechanical advantage to acquisition acceleration so as to decrease the effort in motion to reverse the movement of which is the highest that require greater effort equivalent to about $(17.5 \mathrm{~kg})$ plus the original body weight.

Kinematics differences in the angles of the body under study:

The researcher attributed this difference to the running technique differed as a result of the different running angle, and clearly demonstrates it in different angles of the knee and ankle during the three stages, as it produces a difference as a result of change of the gravity center of the body resulting from changing the vertical axis of the body.

This in turn led to the attempt to overcome the body to keep the weight of the body in the vertical center axis of the body to change the body angles.

Two legs, one of the open movement chains 
(Opened Kinetic Chain), which can be controlled by the player without affecting the other angle, unlike closed movement chains (Closed Kinetic Chain) which always resulted in a total of certain angles is also considered. Which it gave the body the freedom to change the hip, knee and ankle angles permanently and free to save one of:

- Keeping the center of mass within the vertical axis of the body.

- Resistance the biomechanical variables which varies with the surface of the run inclination.

- The percentage increase in the total incident force effect on the body weight in the case of the running on positive Angle

The percentage decrease in the total incident force effect on the body weight in the case of the running on negative Angle

All these variables that led to the existence of differences kinematics to run in case of changing the level of the running surface.

Arms have helped to overcome the influence on the weight of the body in the case of positive running power in the second and third types (running Bzaah mile positive and mange an angle of a negative slope), where he played, changed the position of the arms in an attempt to change the Mrdz the weight of the body and push forward while running at an angle wavelengths.

As the player to change the weight of the body and push the center back with the help of arms while running a negative angle.

Thus, the answer to the first question of the study achieved a "what are the Kinematics differences between the three methods to running on a multiinclination?"

- conclusions and recommendations:

conclusions:

Within the limits of the research objectives, the research questions and the results the researchers concluded the following : -the Kinematical characteristics of Running on zero Angle, the time was $(0.76 \mathrm{~s})$ which is less time to run, and hit horizontal velocity $(209.41 \mathrm{~m} / \mathrm{s})$ and acceleration was $(1075 \mathrm{~m} / \mathrm{s} 2)$. 
-the Kinematical characteristics of Running on positive Angle, the time was $(0.80 \mathrm{~s})$, the second less time to run, and hit horizontal velocity (195.82 $\mathrm{m} / \mathrm{s}$ ) and acceleration was $(91.63 \mathrm{~m} / \mathrm{s} 2)$.

-the Kinematical characteristics of Running on negative Angle, the time was $(0.86 \mathrm{~s})$ which is most time to run, and hit horizontal velocity $(177.2 \mathrm{~m} / \mathrm{s})$ and acceleration was (80.49 $\mathrm{m} / \mathrm{s} 2$ ).

- There were Kinematics differences between the three types of running under study.

- Running on positive Angle has a biggest mechanical load.

- The foot decrease velocity in 2nd phase at running on positive Angle what causes decrease acceleration.

- Body involuntarily
working to change the leg angles commensurate with the center of mass and leaving him on the vertical axis.

Forces sum increases on the body about $25 \%$ of body weight in the case of running a positive inclination angle of $+15^{\circ}$.

- $\quad$ Forces sum decreases on the body at about $25 \%$ of body weight in the case of running a negative angle of inclination of $-15^{\circ}$

-Study kinematics differences in the arms and center of gravity while running a multiinclination.

\section{recommendations:}

In light of the outcome of the results of the study, the researcher to formulate recommendations of the study are as follows:

- Use running inclination angle zero in cases where the treatment of injuries that have mechanical-load actually on the knee and foot wrist in less. - Use running inclination angle is positive in cases of training on strength and endurance component of development as it is the mechanical-load reality on the knee and foot wrist in the large.

- The use of running a negative angle of inclination in cases of training maximum velocity element and carry velocity development, where the player can change the velocity of the body by controlling the degree of inclination trunk and not the use of the foot for a worker to stop the body. 
More research on mechanical running in cases of mechanical factors surrounding the change and which ones (friction - Fluid) coefficient>

- $\quad$ More research on the use of mechanical running multigravity treadmill.

\section{References:}

Arabic references:

1. Ehab Adel Abdul Basser, Adel Abdul Basser, 2005, biomechanical analyze and Integration of theory and practice, Union publishing, portsaid.

2. Khedr mohammedd ah shybany, Osama Ahmed alany, 2008, General Physics for high education, vol2, Alkhregy publishing, K.S.A

English references:

3. Bradley S. Neal, Christian J. Barton, Rosa Gallie, Patrick O'Halloran, Dylan Morrissey, 2016, Runners with patellofemoral pain have altered biomechanics which targeted interventions can modify: A systematic review and meta-analysis, Gait \& Posture, Volume 45, March 2016, Pages 69-82.

4. Darryl Cochrane, 2013, The sports performance application of vibration exercise for warm-up, flexibility and sprint velocity European Journal of Sport Science, 2013, Volume 13, Number 3, Page 256.

5. Deepak Kumar, Kelly McDermott, Haojun Feng, Veronica Goldman, Anthony Luke, Richard B. Souza, Frederick M. Hecht, 2015, Effects of Form-Focused Training on Running Biomechanics, $\quad P M \& R$, Volume 7, Issue 8, August 2015, Pages 814-822.

6. J.D. willson et al (sex differences in running mechanics and patellofemoral joint kinetics following an exhaustive run). (2016). Technology \& Business Journal, , 262.

7. Karsten Hollander, Dieko Riebe, Sebastian Campe, Klaus-Michael Braumann, Astrid Zech, 2014, Effects of footwear on treadmill running biomechanics in preadolescent children, Gait \& Posture, Volume 40, Issue 3, July 2014, Pages 381-385.

8. Krzysztof Mackala, 2013, Differences Between the Elite and Subelite Sprinters in Kinematic and Dynamic Determinations of Countermovement Jump and 
Drop Jump, Journal of Strength and Conditioning Research, 2013, Volume 27, Number 11, Page 3021.

9. Laura Hutchison, Rolf Scharfbillig, Hayley Uden, Chris Bishop, 2014, The effect of footwear and foot orthoses on transverse plane knee motion during running - A pilot study, School of Health Sciences, University of South Australia, City East Campus, Adelaide, Australia.

10. Sterzing, T., Apps, C., Ding, R., \& Cheung, J. T. (2014). Running on an unpredictable irregular surface changes lower limb biomechanics and subjective perception compared to running on a regular surface. Journal of Foot and Ankle Research, 7 doi:http:// dx.doi. org/10.1186/1757-1146-7-S1-

A80 2016, The Relationships between Age and Running Biomechanics, Health \& Medicine Week, NewsRx.
11. Thomas Haugen and Martin Buchheit, 2015, Sprint Running Performance Monitoring: Methodological and Practical Considerations, Sports Medicine, 2015.

12. Kim, Maeng-kyu; Kim, Chon-sub; Kim, Yong-woo; Jung, Hye-Young; Joe, Hyun-duck; Kim, Nam-joo, 2016, Medicine \& Science in Sports \& Exercise, American College of Sports Medicine Publication.

13. D,Gordon E,Rbertson; Gary kamen 2004, Research Methods in Biomechanics, Human Kinetics publisher Internet references:

14. http://42.195km.net/e/tre $\operatorname{adsim} / /$

15. http://www.hillrunner.co $\mathrm{m} /$ training/tmillchart.php

16. http://www.shapesense.c om/fitness-

exercise/calculators/walkingcalorie-burn-calculator.shtml 17. https://www.ncbi.nlm.ni h.gov/pubmed/10862544 